\title{
Article
}

\section{Predicting Site Indices of Japanese Cedar Plantation in Niigata Prefecture using Environmental Factors}

\author{
Sri Lestari Munajati ${ }^{* 1}$, Nobuyuki Abe ${ }^{* 1}$ and Masami Tsukahara ${ }^{* 2}$
}

\begin{abstract}
The objectives of this study were (a) to evaluate the correlation of environmental factors with the site index of Japanese cedar, and (b) to develop the best-fit equation model for the site index. Multiple regression models for a site index of sugi plantation in Niigata Prefecture were constructed using environmental factors as independent variables. The environmental factors used were climate data (snow depth), soil type data and topographical data (aspect, slope, elevation, hillshade, distance from ridge, wetness and curvature). Through a backward stepwise procedure, the elevation, hillshade and soil type were selected for a best-fit regression model. In this model the multiple correlation coefficient was 0.523 , and standard error estimate $2.84 \mathrm{~m}$.
\end{abstract}

Keywords: GIS, site index of sugi plantation, environmental factors, multiple regression model

\section{INTRODUCTION}

Japanese cedar (Cryptomeria japonica), 'sugi' in Japanese, is the most economically important timber species in Japan. It has been cultivated over extensive areas for timber and as ornamental trees in temples and shrines. The total area of forest in Japan is 25.212 million ha, and man-maid forests occupy about 10.327 million. The percentage of sugi plantation forests is approximately $43.8 \%$ (4.536 million ha) of the whole man-made forests. Niigata Prefecture has about 142 thousand ha of sugi plantation (MSCIE, 1995).

Recently in Japan, many researchers use the topographical factor to predict the site index such as sugi plantation (CHEN and ABE, 1999), sugi and hinoki (TERAOKA et al., 1991), and Japanese larch plantation (NISHIZAWA et al. 1965 and MitSUDA et al. 2001). Outside of Japan, also many researchers estimate the site index using environmental factors; for example, IVERSON et al. (1997) used GIS-derived data to develop the integrate moisture index to predict forest composition and productivity of Ohio Forest; CHEN et al. (1998) predicted the site index of trembling aspen by

\footnotetext{
Corresponding author: Nobuyuki Abe

${ }^{* 1}$ Faculty of Agriculture, Niigata University, Ikarashi, Niigata 950-2181 Japan

${ }^{* 2}$ Niigata Forest Institute, 2249-5 Unotoro, Murakami 958-0264 Japan
}

developing multiple regression using climatic, topographic, soil physic and chemical properties; WANG (1998) developed a model for site index conversion among species (lodge pole pine and white spruce).

It is efficient to analyze environmental factors using the Geographic Information System (GIS). GIS is a powerful set of tools for collecting, storing, retrieving, manipulating, analyzing, transforming and displaying both spatial and nonspatial data obtained from the real world, which acts as a decision- support system involving the integration of spatially referenced data in a problem solving environment (BURROUGH and McDonNELL, 1998). Thus, GIS provides a comprehensive tool to predict the site index from environmental factors.

The objectives of this research are (a) to evaluate the correlation of environmental factors with the site index of Japanese cedar, and (b) to develop the best-fit equation model for the site index.

\section{MATERIALS AND METHODS}

Study Area

The study area is located in Niigata Prefecture, Japan. The area of Niigata Prefecture is $12,582.29 \mathrm{~km}^{2}$ which extends from northeast to southwest through about 2 degrees of latitude $36^{\circ} 40^{\prime}-38^{\circ} 40^{\prime} \mathrm{N}$ and longitude $137^{\circ} 42^{\prime}-140^{\circ} 00^{\prime} \mathrm{E}$ (Niigata Yearbook, 2002).

The feature of the climate in Niigata Prefecture is typical of districts with the Japan Sea type climate; comparatively low 
precipitation in the summer and high in the winter. The maximum annual precipitation is about $1,708 \mathrm{~mm}$ in Niigata city and $3,300 \mathrm{~mm}$ in the mountainous area. Niigata Prefecture is known as a snow country, with a snow depth of less than 50 $\mathrm{cm}$ in the city and more than $500 \mathrm{~cm}$ in the mountainous area. In 2002 , mean temperature was about $26.4^{\circ} \mathrm{C}$ in summer and $1.5^{\circ} \mathrm{C}$ in winter. The relative humidity of the study area was $70-$ 98\% (Niigata Yearbook, 2002). The study area has topography between plate and mountainous areas. Elevation is between 55 and $1322 \mathrm{~m}$ above mean sea level (msl) and slope is between 5 and 38 degree.

The vegetation in the study area consists of coniferous and broadleaf species. Coniferous species form most of the plantation forest. Almost all coniferous species are sugi (Cryptomeria japonica) and others are akamatsu (Pinus densifloria) and kuromatsu (Pinus Tunbergii). Broadleaf species are mostly a secondary forest. Some of the broadleaf species are buna (Fagus crenata), mizunara (Quercus mongolica), hounoki (Magnolia obovata) and tochinoki (Aesculus turbinate) (MSCIE, 1995).

Data

The data used in this research were obtained from a ground survey, yield book, forest inventory, manuscript map and digital mesh point data. Environmental data are summarized in Table 1. The manuscript map data set was obtained from the soil type map (Niigata Prefecture, 1973; 1976; 1978a; 1978b; 1979a; 1979b), scale of 1:50,000, and digital map data sets were formed from the digital map with a $50 \mathrm{~m}$ grid elevation (mesh-point data) and administrative boundary of Niigata Prefecture. Table 2 summarizes the data of the field survey.

The plot were established based on the Niigata Prefecture Forestry Division method (plot size; $40 \mathrm{~m} \times 40 \mathrm{~m}$, tree size; diameter of breast height, total height, tree condition; healthy, unhealthy, straight and oblique tree for each tree in the plot). Reasonable plots were set up for the uniform distribution of sugi plantation (92 plots, size; $40 \mathrm{~m} \times 40 \mathrm{~m}$ ), mature stand, and variation of topographic factors. Ground survey was conducted in June-November 2003 at each location shown in Fig. 1.

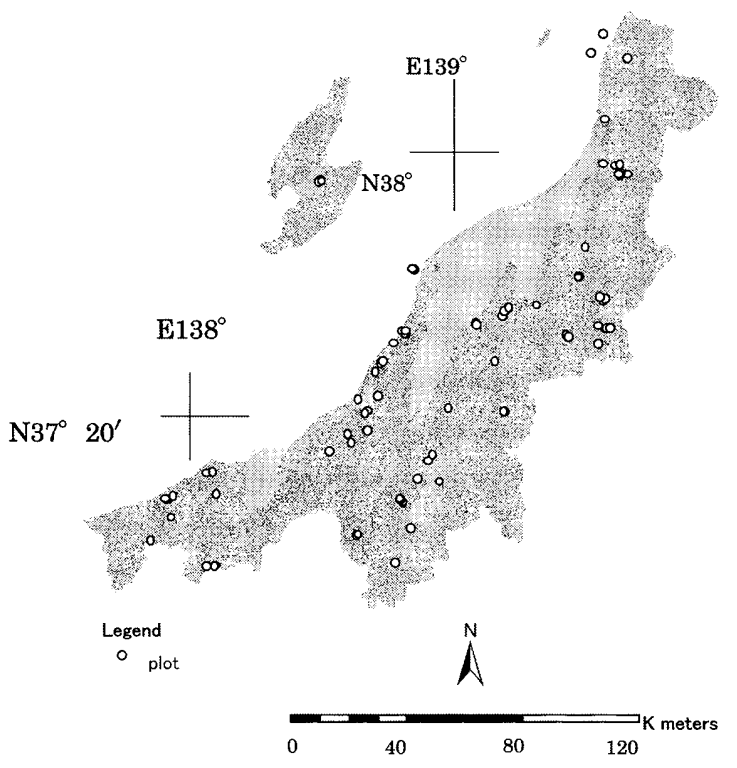

Fig. 1 Location of each plot

Table 1 Summary of the environmental data

\begin{tabular}{clrrrr}
\hline No & \multicolumn{1}{c}{ Items } & Minimum & Maximum & \multicolumn{1}{c}{ Mean } & \multicolumn{1}{c}{ SD } \\
\hline 1. & Snow depth $(\mathrm{cm})$ & 0 & 428 & 130.24 & 75.33 \\
2. & Slope $\left(^{\circ}\right)$ & 5 & 38 & 17.56 & 8.05 \\
3 & Aspect $\left(^{\circ}\right)$ & 3 & 358 & 204.01 & 104.53 \\
4. & Elevation $(\mathrm{m})$ & 55 & 1322 & 374.19 & 262.44 \\
5. & Curvature & -1.79 & 1.49 & 0.01 & 0.75 \\
6. & Hillshade & 150 & 254 & 225.53 & 26.17 \\
7. & Distance from ridge (m) & 0 & 108 & 40.31 & 29.03 \\
8. & Wetness & -4.66 & 6.54 & -2.20 & 1.78 \\
\hline
\end{tabular}

Table 2 Summary of the field survey data

\begin{tabular}{clrrrr}
\hline No & \multicolumn{1}{c}{ Items } & Minimum & Maximum & \multicolumn{1}{c}{ Mean } & \multicolumn{1}{c}{ SD } \\
\hline 1. & Average DBH $(\mathrm{cm})$ & 21.60 & 50.70 & 34.89 & 5.45 \\
2. & Average H (m) & 11.86 & 28.92 & 21.44 & 3.69 \\
3. & Average HDT (m) & 19.22 & 34.40 & 26.74 & 3.44 \\
4. & Volume/ha (m $\left.{ }^{3} / \mathrm{ha}\right)$ & 151.22 & 1372.36 & 713.29 & 241.68 \\
5. & 16.56 & 111.74 & 67.01 & 17.41 \\
6. & Basal Area $\left(\mathrm{m}^{3} / \mathrm{ha}\right)$ & 194 & 1244 & 674.61 & 194.19 \\
7. & Age (yr) & 36 & 81 & 67.18 & 7.16 \\
\hline
\end{tabular}


Using the spline interpolation command in the ARC-GIS 3D Analyst, we used 'Digital Map 50-m grid' published by Japan Geographic Survey Institute to construct the DEM data in this research. Spline is a general-purpose interpolation method that fits a minimum-curvature surface due to the input points. This method is best for gradually varying surfaces such as elevations, water-table depths and pollution concentrations (BоOTH, 2000). After the DEM data was built, the environmental factors were calculated.

Site Index

Site index is defined as the average height of dominant trees in a forest stand at a reference age. In this study, the average height of dominant trees in each plot was calculated as average tree height of the highest $20 \%$ trees, and the stand age was obtained from Forest Database (Niigata Prefecture,1999). As reported by NisHIZAWA et al. (1965), the site index of each plot refers to the guide curve that was developed based on field survey data (92 values) and data from Yield Table (167 values) (Niigata Prefecture, 1980) with the reference age at 60 years. The guide curve is calculated by the Mitscherlich equation using SPSS (11.5.1J) program (Equation (1)).

1) Decision of guide curve

$$
Y t=41.5452 \times\left(1-\mathrm{e}^{\left(-0.01446^{6}\right)}\right)
$$

Where,

$$
\begin{aligned}
& Y t \text { : average height of dominant tree } \\
& t \text { : stand age }
\end{aligned}
$$

The guide curve shown in Fig. 2.

2) Standard deviation of tree height at each stand age

We calculated standard deviation of tree height in each age class (5 years interval) from the following formula.

$$
\sigma_{t}=\sqrt{\frac{\sum_{i \in D T}\left(y t_{i}-y y t_{i}\right)^{2}}{n T}}
$$

$y t$; Average dominant tree height of age $t$ of each plot $y y t$; Average dominant tree height of age $t$ from guide curve $D T$; Set of data of age class $T$

$T$; age class

$n T$; Number of data at $T$

Relationship between $\sigma_{\mathrm{t}}$ and $\mathrm{t}$ is obtained as follows.

$$
\sigma_{\mathrm{t}}=0.02037 \times t+1.5606
$$

The value of $\sigma_{t}$ for each age class is calculated by this equation. Assuming that the difference between site index value $(Y)$ and the tree height at age 60 obtained from the guide curve $\left(\mathrm{Y}_{60}\right)$ is proportional to $\sigma \mathrm{t}_{60}$, and that between $y t$ and $y t t$ is proportional to $\sigma_{\mathrm{t}}$

$$
y t-y t t / \sigma_{\mathrm{t}}=Y-Y_{60} / \sigma_{60}=R Y
$$

Thus, tree height at each age class (yts) with site index $Y$ is calculated by

$$
y t s=y y t+R Y \sigma_{\mathrm{t}}
$$

For instance, the average height of dominant tree at age 30 is obtained as follows.

From formula (1) $y t t$ at age 30 is $14.62 \mathrm{~m}$, and $\sigma_{30}=2.17 y t t$ at age 60 and $\sigma_{60}$ is 24.1 and 2.78, respectively. Applying these values to formula (4),

$$
\begin{aligned}
& Y-Y_{60} / \sigma_{60}=20-24.1 / 2.78=-1.4748 \\
& y t s=14.62-1.4748 \times 2.17=11.42 \mathrm{~m}
\end{aligned}
$$

Repeating such calculation for the stands at various ages, we can obtain site index curves.

To estimate $S I$ of each plot,we calculated from the following formula.

$$
S I=Y_{60}+(y t-y y t) \frac{\sigma_{60}}{\sigma_{t}}
$$

SI; Site index of plot

$y t$; Average dominant tree heit of $t$

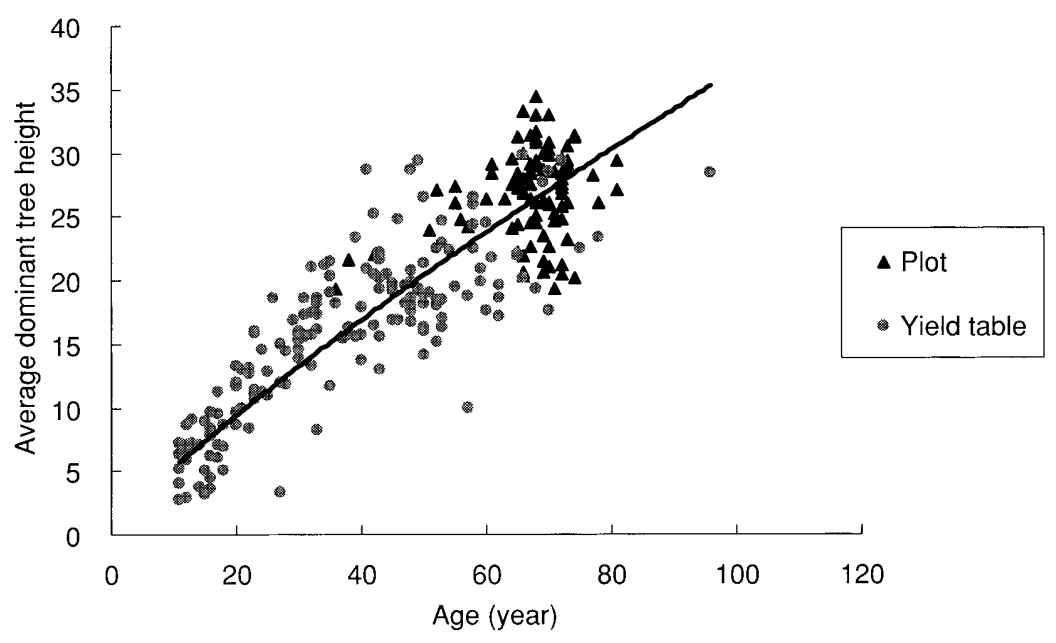

Fig. 2 Site index curve of sugi 
$y y t$; Average dominant tree height of age $t$ from guide curve $Y_{60}$; Average dominant tree height from 60 years (standard age) from guide curve

$\sigma_{60}$ and $\sigma_{t}$; Standard deviation of tree height in 60 years (standard age) and age $t$

\section{Environmental Factors}

The environmental factors that were used to predict the sugi site index were climate data (snow depth), soil type data, topographical data (aspect, slope, elevation, hillshade, distance from ridge, wetness and curvature). These environmental factors were selected for this research based on the assumption that these factors were highly correlated with the site index according to some previous studies (NISHIZAWA et al., 1965; TERAOKA et al., 1991). Table 2 summarizes the data of these factors. 92 plots are used for calculating the relationship between environmental factors and site index.

1) Elevation

Elevation affects various factors such as snow depth, microclimate and soil. However, in this study elevation should be analyzed from the viewpoint of the correlation with the site index. NishizaWA et al. (1965) considered elevation and the soil factor as factors affecting the site index. We can not estimate the coefficient of the correlation between elevation and soil type. On the other hand, the correlation of coefficient between elevation and snow depth is shown 0.57 indicating a little high correlation.

2) Snow depth

Niigata Prefecture is a snowy area with heavy snow cover in many areas especially in mountainous areas such as Myoko, Tsugawa and Joetsu. The effect of heavy snow accumulation on trees usually leads to deformation of the trees such as branch bending, tearing and breakage. Accumulation of snow by drifting can have different effects on trees, generally it delays snowmelt and reduces the growing period accordingly (BÉGIN and BoIvIN, 2001). At the end of each winter we can see sugi trees damaged by snow. Therefore, the snow depth influencing sugi growth was represented by the site index.

3) Soil type

The private sugi forests in Niigata Prefecture have 21 soil types; the five major kinds were $\mathrm{BD}, \mathrm{BD}(\mathrm{d}), \mathrm{BE}, \mathrm{BlD}$ and $\gamma \mathrm{BD}$ (Niigata Prefecture, 1973-1979). Plot samples in this study were obtained from only the two representative soil types of $\mathrm{BD}, \mathrm{BD}(\mathrm{d})$ which were detected on the soil map attached to the report of right tree for right site (Niigata Prefecture, 19731979). To represent soil type in the following regression analysis, we used a dummy variable coded 1 for BD and 0 for BD(d) (SALL, 1981).

4) Aspect

Aspect is the compass direction toward which a slope faces, and was measured in degrees from north in clockwise direction (ESRI, 1994). Aspects were divided into four classes according to the degrees: (1) north, $0-45^{\circ}$ and $315-360^{\circ}$; (2) east, $45-135^{\circ}$; (3) south, $135-225^{\circ}$ and (4) west, $225-315^{\circ}$.

5) Slope

Slope is a measure of change in surface area, expressed in degrees or as a percentage (ESRI, 1994). Slop was used to calculate the relationship between site index and environmental factors. The slope range of field survey data was between 5-38 degrees.

6) Hillshade

The environmental factors, hillshade, curvature, flow accumulation, distance from ridge and wetness were derived from the digital elevation map (DEM).

$$
\begin{aligned}
& \text { Hillshade }=255.0 \times((\cos (\text { Zenith })+\cos \text { (Slope }) \\
& \quad+(\sin (\text { Zenith })+\sin (\text { Slope }) \times \cos (\text { Azimuth-Asp }))
\end{aligned}
$$

Hillshade describes intensities of solar radiation varying with the slope angle, aspect, position and accounts for shading from adjacent hills (IvERSON et al. 1997). According to SASE et al. (1998), the Japanese cedar is more sensitive to shortage of water than other conifers during the summer season in Japan. Therefore, hillshade was calculated in 2003 summer season at the longest day, which was June $23^{\text {th }}$ with daylight of 14 hours 38 minutes, sun direction (azimuth) of 300 degrees and solar elevation (altitude) of 77 degrees. This method was similar to that of MrTSUDA et al. (2001), who predicted the Japanese larch site index in Hokkaido. Hillshade is calculated using 'Hillshade' command in Spatial Analyst or 3D Analyst of ARCGIS Software (ESRI, 1994). By default, shadow and light are shades of gray associated with integer from 0 to 255 . A low value represents low solar radiation or area shaded by the adjacent hill and high value represents high solar radiation or area free from shading.

Range of the hillshade data was between 150 and 254 with an average of 225.53 and standard deviation of 26.17 .

7) Distance from ridge

Distance from ridge (DR) is calculated as the distance from the ridge obtained as a line vector data through 'Distance' commands in Raster Calculator in Spatial Analyst of ARC-GIS software (ESRI, 1994). Flow accumulation data is used as an input data in calculating distance from ridge. Flow accumulation (FA) is calculated as the accumulated water flowing down a slope (IvERSON et al. 1997) and the algorithm for FA was given in JENSON and Domingue (1988). In ARC-GIS software, it is calculated using the 'Flow accumulation' command in Workstation. At the ridge tops, flow accumulation may be minimum and the valley bottoms it may be maximum. Therefore, the ridge top will have a minimum value and the valley bottoms will have a maximum value.

Range of distance from ridge data was between 0 and $108 \mathrm{~m}$, with an average of $40.31 \mathrm{~m}$ and standard deviation was $29.03 \mathrm{~m}$.

8) Wetness

Wetness index (BEVEN and KIRKBY 1979) is an index of moisture retention. Wetness index is shown in Equation 6, which is calculated using Raster Calculator command in 
Spatial Analyst of ARC-GIS software. The higher value represents the moisture area and the smaller value represents the non-moisture area.

Wetness $=$ Ln (flow accumulation $/ \tan ($ slope) $)$

Range of wetness was between -4.66 and 6.54 , with an average of -2.20 and standard deviation is 1.78 .

9) Curvature

Curvature measures the shape of the landscape: whether it is flat, convex or concave (IvERSON et al., 1997; BURROUGH and MCDonNELL, 1998) and the algorithm for curvature as a landform characterization is given in BLASZCZYNNSKY (1997). The positive curvature represents the concave area and the negative curvature represents the convex area. Curvature is calculated using 'Curvature' command in Workstation of ARCGIS Software.

Range of curvature data was between -1.79 and 1.49 with the average of 0.01 and standard deviation of 0.75 .

Data analysis

Parameters effective for estimating site index were selected by multiple regression analysis adopting stepwise procedure. Variables were selected by the stepwise procedure at significant level of 0.05 .

\section{RESULTS}

All of the environmental factors (9 factors) were used for estimating the site index model of sugi plantation. Variables selected by stepwise procedure for best-fit regression model were elevation, hillshade and soil type, and Table 3 shows the regression equation for determining the side index using these three variables. The elevation and hillshade are shown by numerical values, but soil type are shown by letters as BD and $\mathrm{BD}(\mathrm{d})$. Therefore, to form the multiregression equation shown in Table 3, we expressed $\mathrm{BD}$ and $\mathrm{BD}(\mathrm{d})$ as 0,1 . Multiple correlation coefficient was 0.523 (Determination coefficient; 0.274 ), and the correlation was not so high. However, standard error of estimate was $2.84 \mathrm{~m}$ and analysis of variance shown in Table 4 was significant at $1 \%$ level, showing the validity of this equation. Among the three variables in this equation, soil type showed the highest standardized partial correlation coefficient followed by hillshade and elevation in this order (Table 5). Although the soil type used in the site index table in the study on the right tree for the right site in Niigata prefecture were $\mathrm{B}$, $\mathrm{BD}(\mathrm{d}), \mathrm{BD}, \mathrm{BE}, \mathrm{BF}$ and $\mathrm{BD}$, the soil type included in the present study was only $\mathrm{BD}(\mathrm{d})$ and $\mathrm{BD}$ but it correlated with the site index.

\section{DISCUSSION}

In the backward stepwise procedure, effective variables are selected stepwise, and the selection of variables is not arbitrary. From 1966, the countrywide survey of sugi stand land productivity in national and private forests started, and the number of quantified sample data all over the country exceeds 20,000. SAKAGUCHI et al. (1983) examined the factors that affected site index in each region. According to these studies soil type had the greatest effect on the site index in most of the regions. In the stands of trees other than sugi, the soil type has been reported to have the greatest effect on site index (NishizaWA et al. 1965, Corona et al. 1998, YAmANE 1990). Results of the studies on the right tree for the right site also indicated the soil type as an important factor in estimating site index. In the study on the right tree for the right site in Chuetsu forest planning area, the coefficient of partial correlation of site index with the soil type was 0.59 (calculated by Quantification Method I). These results suggest that the soil type is an indispensable factor for estimating site index. According to SAKAGUCHI et al. (1983), the effect of elevation, though variable, is large in Niigata, Akita, Nara, Kumamoto

Table 3 Regression model for predicting site index from environmental factors

\begin{tabular}{ccc}
\hline Model & Multiple correlation coefficient & SEE \\
\hline $\mathrm{SI}=31.233-0.005$ (elevation) --0.026 (hillshade) +1.758 (soil type) & 0.523 & 2.842 \\
\hline
\end{tabular}

Elevation and hillshade are observed values. Soil type of $\mathrm{BD}, \mathrm{BD}$ (d) mean as $0,1$.

SEE; standard error of estimate

Table 4 Analysis of variance

\begin{tabular}{lccc}
\hline Source & df & SS & F \\
\hline Regression & 3 & 63.304 & 7.837 \\
Error & 88 & 8.078 & \\
Total & 91 & & \\
\hline
\end{tabular}

Table 5 Standardized partial correlation coefficient of variables

\begin{tabular}{lcr}
\hline Variable & Standardized partial correlation coefficient \\
\hline Elevation & -0.368 & ${ }^{* *}$ \\
Hillshade & -0.282 & ${ }^{* *}$ \\
Soil type & 0.330 & ${ }^{* *}$ \\
\hline & & ${ }^{* *}$ significant (at $1 \%$ level)
\end{tabular}




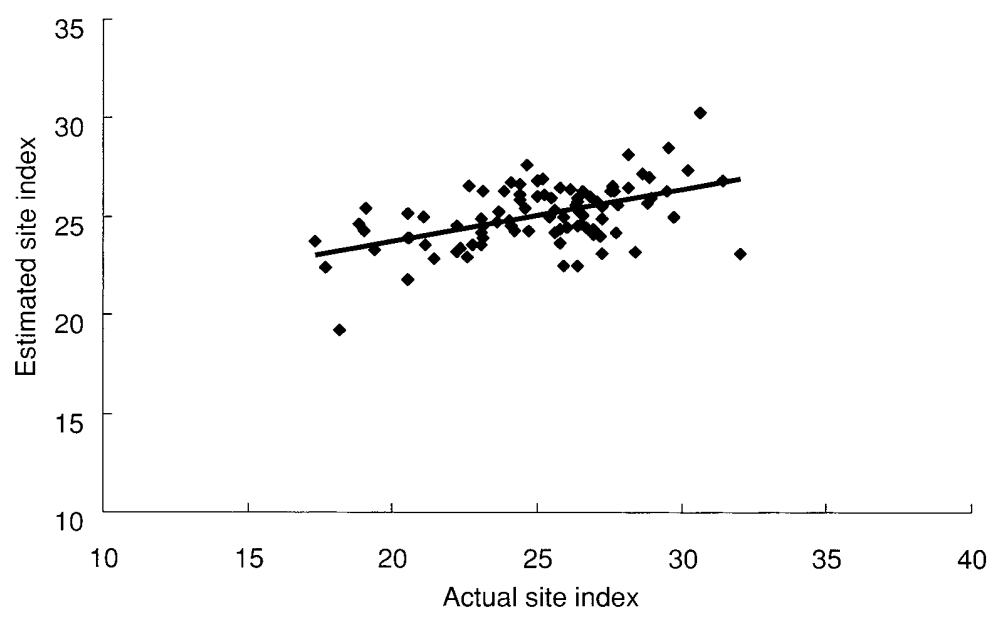

Fig. 3 Relationship between actual site index and estimated site index

and other prefectures. In the score table of Niigata prefecture, elevation showed a high coefficient of partial correlation with site index next to soil type. Thus, the soil type and elevation selected in this study support the previous reports. NISHIZAWA et al. (1965) reported that the coefficient of correlation between soil type and elevation was 0.244 (calculated by Quantification Method I). At a higher elevation, humus does not decompose, and it shows a correlation with the soil type. In the present data, soil type is given by dummy variables.

On the other hand, there are some reports on the method of site index estimation without using information on soil type. Mitsuda et al. (2001) estimated side index of larch using topographical factors obtained from GIS. The factors selected by stepwise procedure were average slope gradient, degree of exposure and shading. TERAOKA et al. (1991) determined the effective water storage capacity, degree of exposure and effective relief as the moisture environment of forest, and obtained site index using these factors as independent variable. The multiple correlation coefficient of the estimation was 0.832. IVERSON et al. (1997) estimated moisture retention of forest from the amount of hillshade. The amount of hillshade is a measure of the intensity of solar radiation, and is used to estimate the dryness of slope. Thus, the cases of analyses using the factor obtainable from GIS are increasing. However, the areas investigated by IVERSON et al. (1998), Mrtsuda et al. (2001) and TERAOKA et al. (1991) were $475,3,735$ and $150 \mathrm{ha}$, respectively, and were small watersheds.

Topographic factors might be more effective than soil type for small watershed. It is important to consider the area of the target site when estimating the site index. In the present study, we modeled the site index using data collected all over the prefecture. The objective of the present study was to estimate the soil index of the area where the studies on the right tree for the right site had been conducted based on the young stand, using mature stand data. Thus, various kinds of data were collected from all over the prefecture. The multiple regression coefficients were not high in spite of the use of as many as 9 factors. Thus, forming a prediction formula for the whole prefecture is difficult. In this study, soil type was selected as an effective factor and the previous studies on the right tree for the right soil also showed the soil type as an effective factor. In all prefectures of Japan, soil type has already been mapped based on the results of the studies on the right tree for the right site. Digitization of these soil maps for the use of GIS may make it easy to use the soil type as a factor for estimating site index, and increase the accuracy of the estimate.

In this study, we examined snow depth as a meteorological factor that influences the growth of Japanese ceder plantation. Precipitation, solar radiation, temperature, etc. also affect the growth of the ceder plantation. However, we examined as many as 92 plots, and we could not form regression equations including multiple meteorological factors. The correlation of site index with meteorological factors other than snow depth will be examined in separate studies.

We showed actual site index of a plot and site index presumed using multi regression on Fig. 3. The tendency for presumed accuracy to decline was showed for the plot with lower site index

\section{CONCLUSION}

Among the data obtained from all over Niigata Prefecture, only altitude, soil type and hillshade affected the value of site index, which differed from the results obtained in a small watershed. Soil type is an important factor for predicting site index in the whole prefecture. In Niigata prefecture, site index has been estimated using 9 items (elevation, Aspect, Slope, Soil type, Deposition type, Local topography, Surface horizon geology, Snow depth, Region) by Quantification theory I. But the data of the investigation on 
mature stand suggested the necessity of reappraisal of the items.

\section{ACKNOWLEDGEMENT}

This study was based on the data collected by the staff of Niigata Forestry Research Institute. We would like to thank Mr. Takakazu Hoshina director of Niigata Forestry Research Institute. This research was partially supported by the Japan Society for the Promotion of Science.

\section{LITERATURE CITED}

BLASZCZYNSKI, J.S., (1997): Landform characterization with geographic information systems. PE \& RS. 63: 183-191

BÉgIN, Y. and Borvin, S., (2001): Tree-Ring Dating of Past Snow Regimes. In Snow Ecology: An Interdisciplinary Examination of Snow-Covered Ecosystems. Edited by Jones, H.G., J.W. Pomeroy, D.A. Walker and R.W. Hoham. Cambridge University Press.

Beven K.J. and KirkBy M.J.,(1979): A physically Based,Variable Contributing Area Model of Basin Hydrology. Hydrological Sciences Bulletin, 24(1): 43-69

Bоотн, B., (2000):. Using ArcGIS 3D Analyst. Environmental Systems Research Institute (ESRI). California. USA

BurRough, P.A. and MCDonnell, R.A., (1998): Principal of Geographical Information Systems. Oxford University Press. Oxford

Chen, H.Y.H., KuInKa, K. and Kabzems, R.D., (1998): Site index, site quality and foliar nutrients of trembling aspen: relationships and predictions. Can. J. For. Res. 28: 1743-1755

Chen, J. and ABe, N., (1999): Site classification for sugi plantation using GIS. J. For. Plan. 5: 1-8

Corona, P., Scotti, R. and Tarchiani, N.,(1998): Relationship between environmental factors and site index in Douglas-fir plantations in central Italy. For. Ecol. Manage. 110: 195-207

ESRI, (1994): ARC/INFO Data Management. Environmental Systems Research Institute. Redland. USA

Iverson, L.R., Dale, M.E., ScotT, C.T. and Prasad, A., (1997): A GISderived integrated moisture index to predict forest composition and productivity of Ohio forest (USA). Land. Ecol. 12: 331-348

Jenson, S.K. and Domingue, J.O., (1988): Extracting topographical structure from digital elevation data for geographic information system analysis. PE \& RS. 54: 1593-1600

Mitsuda, Y., Yoshida, S. and IMADA, M., (2001): Use of GIS-derived environmental factors in predicting site indices in Japanese larch plantations in Hokkaido. J. For. Res. 6: 87-93
MSCIE (Meeting of Sugi Characteristics Investigation and Examination)., (1995): Sugi of Niigata Prefecture (Niigata no sugi). Niigata Forestry Association of Improvement of Niigata Prefecture. Niigata (in Japanese)

Niigata Prefecture., (1973): Report of right tree for right site Kanbara forest planning area-45pp, Niigata (in Japanese)

Niigata Prefecture., (1976): Report of right tree for right site -Sado forest planning area-55pp, Niigata (in Japanese)

Niigata Prefecture., (1978a): Report of right tree for right site Kameda forest planning area-55pp, Niigata (in Japanese)

Niigata Prefecture., (1978b): Report of right tree for right site Chuetsu forest planning area-49pp, Niigata (in Japanese)

Niigata Prefecture., (1979a): Report of right tree for right site Chuetsu forest planning area-55pp, Niigata (in Japanese)

Niigata Prefecture., (1979b): Report of right tree for right site Uonuma forest planning area-54pp, Niigata (in Japanese)

Niigata Prefecture., (1980): Yield Table. Niigata Prefecture, Agriculture, Forestry and Fisheries Division, Conservation Section. 172pp, Niigata (in Japanese)

Niigata Prefecture., (1999): Kaetsu forest planning, 152pp, Niigata (in Japanese)

Niigata Yearbook., (2002): Niigata Prefecture Yearbook. 2002. Niigata Nipposya. Niigata. 549pp (in Japanese)

NishizaWA, M., Mashimo, Y. and KaWABaTA, K., (1965): Estimation method of site index by quantification. Bulletin of the Forestry and Forest Products Research Institute, 176: 1-54 (in Japanese with English resume)

SAKAGUCHI, K (ed.)., (1983): New all the Sugi.Forest Improvement and Extension Association, Tokyo, 629pp (in Japanese)

SALL, J.P., (1981): SAS Regression Applications. SAS Institute Inc. (S. Niimura translated, 1986, Asakura Syoten, Tokyo, 189PP)

SASE, H., TAKamatsu, T. and Yoshida, T., (1998): Variation in amount and elemental composition of epicuticular wax in Japanese cedar (Cryptomeria japonica) leaves associated with natural environmental factors. Can. J. For. Res. 28: 87-97

Teraoka, Y., Masutani, T. and Imada, M., (1991): Estimating site index of sugi and hinoki from topographical factors on maps for forest management. Sci. Bull. Fac. Agric. Kyushu Univ. 45: 125133 (in Japanese with English abstract)

Wang, G.G., (1998): An ecologically based model for site index conversion among species. Can. J. For. Res. 28: 234-238

Yamane, G., Usui, G., Goshu, K., Kikuchi, K. and Terasawa, K., (1990): Multivariate analysis of site factors on afforested Lalix leptolepis Gordon. Bull. Hokkaido For. Res. Inst. 28: 54-63 (in Japanese with English abstruct) 